\title{
LA DEFINICIÓN DEL TESORO EN LAS FUENTES JURÍDICAS ROMANAS
}

\author{
Alfonso AGUdo RuIZ \\ PROFESOR TITULAR DE DERECHO ROMANO \\ UNIVERSIDAD DE LA RIOJA
}

s u m a r i o

I. La definición de Paulo. I.I. Depositio pecunia. I.2. Vetus depositio cuius non extat memoria. I.3. Depositio ut iam dominium non habeat. 2. La definición de Teodosio I. 2.I. Condita monilia. 2.2. Tempore vetustiore. 2.3. Ignotis dominis. 3. La definición de León II y Zenón.

I. La definición de Paulo.

En el contexto del comentario a la cláusula edictal relativa a la fiducia ${ }^{\mathrm{I}}$, Paulo formula, en el libro treinta y uno ad edictum, escrito bajo el principado de Cómodo o, como muy tarde, en los primeros años del principado de Septimio Severo, anterior al $195^{2}$, su

\footnotetext{
I Así, LENEL, Palingenesia iuris civilis, I (Leipzig I889) I027; KÜBLER, s.v. Thesaurus, en P.W.., VI, A I (Stuttgart I936) 7; MAYER-MALY, Thensaurus meus, en Studia in honorem E. Polay (Szeged I985) 284 s., afirma que «Es ist daher vorstellbar, da $\beta$ die Erörterung der zu Verwahrungszwecken eingegangenen fiducia zu einer Abgrenzung von jener depositio pecuniae geführt hat, aus der ein thensaurus entstand. Nicht auszuschließen ist allerdings, da $\beta$ die thensaurus-Definition ursprünglich überhaupt bei der Behandlung des Realkontrakts depositum gegeben wurde und erst später mit D 4I, I, 3I pr zusammengefaßt wurde, als die fiducia aus diesem Text getilgt werden mußte»; SCARCELLA, Una nuova concezione del tesoro alla luce di C.I. Io.I5.I, en Atti dell'Accademia peloritana dei Pericolanto. Lasse di scienze giuridiche, economiche e politiche, 58 (I989) I92 nt. Io. Cfr. BUSACCA, Qualche osservazione sulle innovazioni introdotte dai divi fratres nel regime giuridico del tesoro, en Scritti in onore di A. Falzea, IV (I99I) I47, que añade la cláusula edictal relativa al depósito; s.v. Tesoro, en E.D., XLIV (Milano I992) 387;

${ }^{2}$ Cfr. FITTING, Alter und Folge der Schiften römischen Juristen von Hadrian bis Alexander (Halle igo8) 84.
}

Redur 4 / 2006 
célebre definición del tesoro ${ }^{3}$, que en palabras de Ortega ${ }^{4}$ es la más famosa y completa, coherente, lógica y correcta, hasta donde sea posible calificar una definición con tales adjetivos y, sobre todo, por haber inspirado, en mayor o menor medida, el concepto de tesoro de las legislaciones modernas, incluida la española.

D. 4I, I, 3I, I (Paulus, 3I ad Edictum): Thensaurus ${ }^{5}$ est vetus quaedam depositio pecuniae, cuius non extat memoria, ut iam dominium non habeat: sic enim fit eius qui invenerit, quod non alterius sit. Alioquin si quis aliquid vel lucri causa vel metus vel custodiae condiderit sub terra, non est thensaurus: cuius etiam furtum fit ${ }^{6}$.

${ }^{3}$ Infundadas nos parecen las críticas vertidas a esta definición por SCHULZ, Derecho Romano Clásico, trad. esp. de Santa Cruz Teijeiro (Barcelona I960) 347 s., cuando afirma que la definición de tesoro dada en el Digesto es defectuosa e inaceptable. La afirmación según la cual el tesoro no tiene dueño es ciertamente inexacta, pues con arreglo al derecho sucesorio romano siempre tendría un propietario, aunque éste no pueda ser identificado: non deficit ius sed probatio. Además, pecuniae es palabra inadecuada, puesto que un tesoro puede consistir, por ejemplo, en joyas. Depositio es también una expresión poco feliz pues el tesoro no es una depositio pecunia (esto es, el acto de depositar dinero), sino más bien pecunia deposita. Toda la definición parece ser de origen postclásico y no puede ser utilizada como la base de una exposición de la materia propia del thesaurus. Cfr. BUSACCA, s.v. Tesoro, cit., 387 nt. 72, afirma que la observación de que pecunia es un término que sirve para indicar cualquier cosa de valor objeto de tesoro es inaceptable, ya que los textos clásicos mencionan únicamente la pecunia, mientras que en los postclásicos se produce la extensión del objeto del tesoro; la crítica al término depositio (pecuniae), que Schulz quiere sustituir por deposita pecunia , es meramente formal; la sospecha de que el texto sea de factura postclásica resulta infundada a la luz de la nueva configuración de nuestro instituto en el derecho postclásico. En el mismo sentido, ORTEGA, El concepto romano de tesoro y el artículo 352 del Código Civil, en Estudios jurídicos in memoriam del profesor Alfredo Calonge, II (Salamanca 2002) 739 nt. 2.

${ }^{4}$ ORTEGA, El concepto romano de tesoro y el artículo 352 del Código Civil, cit., 739.

${ }^{5}$ En la Littera Florentina se encuentra el término «thensaurus». Cfr. FORCELLINI, Lexicon totius latinitatis, IV (Padova I945) 724 ss. En el Código de Teodosio, en las Instituciones y en el Código de Justiniano se lee «thesaurus».

${ }^{6}$ La autenticidad de las frases «ut iam dominum non habeat» y «sic enim fit eius qui invenerit, quod non alterius sit» han sido puestas en duda por la doctrina.

Huvelin, Études sur le furtum dans le très ancien romain, I, (Lyon-Paris I915) 276 ss., considera ambas frases interpoladas basándose en razones de forma y de fondo. El citado autor observa que la frase «ut iam dominum non habeat» es sospechosa ya que «ut marquant la conséquence (sans ita, adeo, etc.) après un verbe comme exstare marquant un état (et non une manifestation de la volonté ou de l'activité) souléve bien des doutes». Respecto a la interpolación de la frase «sic enim fit eius qui invenerit, quod non alterius sit» la justifica por la utilización de «sic enim» en el sentido de «d'après cela, dans ces conditions». Añade como razón de fondo que el texto no dice «en sorte qu'on ignore qui est propriétaire», sino que «en sorte qu'il n'y ait plus de propriétaire».

Análoga es la posición mantenida por Beseler, Beiträge zur Kritik der römischen Rechtsquellen, IV (Tubingen I920) I62, en el sentido de no considerar atribuible a Paulo ambas frases. Respecto a la frase «ut iam dominium non habeat» afirma «ist bekanntlich Unsinn. Als wenn es keine Universalsukzession gäbe!».

Bonfante, Corso di Diritto Romano. La proprietà, II, 2 (Roma 1928) 128 nt. 1, observa a la crítica de Beseler que se trata de un error dogmático: si existe un heredero, no hay tesoro en sentido técnico.

Appleton, Le trésor et la iusta causa usucapionis, em Studi in onore di P. Bonfante, III (Milano 1930) 4 ss., en respuesta a las críticas de Huvelin considera que no tienen fundamento. El correlativo (adeo, ita ), dicen los léxicos, puede ser ocultado; por ejemplo, Horacio: Dives erat ut metiretur nummos. Respecto a la frase «sic enim fit eius qui invenerit quod non alterius sit»; «sic enim» se encuentra utilizado 25 veces por los jurisconsultos clásicos: 23 veces en el Digesto, en textos de Pomponio, Gayo, Papiniano, Calistrato, Ulpiano y Paulo (6 textos), Modestino, Licinio Rufo y Hermogeniano, y en dos ocasiones en la Collatio, X, 2, 2 y II, 6, 5. Respecto al argumento de fondo, considera que se trata de un propietario no sólo desconocido, sino sin posibilidad de conocer, lo que equivale en cierto sentido a un propietario

Redur 4 / 2006 
Para Paulo, tesoro es cierto antiguo depósito de dinero, del cual no queda memoria y cuyo dueño no existe, de tal manera que se hace de quien lo encuentra, porque no es de otro; en cambio, si alguien hubiera escondido algo bajo tierra por codicia, miedo o custodia, no hay tesoro, y puede ser objeto de hurto.

Prescindiendo ahora del régimen de la adquisición, que como hemos visto ha centrado la atención de la doctrina, Paulo establece los requisitos que ha de reunir el tesoro para que jurídicamente pueda ser considerado como tal:

a) consistente en dinero;

b) enterrado;

c) inmemorialidad del depósito;

d) inexistencia del propietario;

Por otra parte opone, de forma explícita o implícita, los impedimentos para su configuración jurídica:
a) constitución reciente;
b) existencia del titular;
c) finalidad actual del depósito;

inexistente. Ello sucederá cuando el depósito además de ser antiguo, se haya perdido su memoria. A la crítica de Beseler, Appleton considera que tiene razón, pero la cuestión reside en saber dónde están esos sucesores universales, esos herederos de los herederos de un propietario desconocido por definición. Igualmente, aunque el propietario primitivo sea conocido, puede que no lo sean sus sucesores.

Para el citado autor, únicamente es rechazable la segunda frase «sic enim fit eius qui invenerit quod non alterius sit» como glosa o interpolación. Además de razones formales entre la primera y la última parte del texto, el citado autor pone el acento en el reparto del tesoro descubierto: «C'est-à-dire la moitié», en contradicción con los datos ofrecidos por otras fuentes y, particularmente, con la regulación adrianea vigente en tiempos de Paulo. No es posible que Paulo haya escrito que el tesoro en cuanto res nullius corresponde por ocupación al descubridor.

Longo, Corso di Diritto Romano. I diritti reali (Padova 1962) 109 ss., también se hace eco de las críticas de Huvelin, Beseler y Appleton, afirma que presentan el defecto fundamental de todas las críticas que se basan esencialmente sobre elementos externos, considerando escasamente la sustancia jurídica de los textos. Respecto a la frase «sic enim fit eius, qui invenerit quod non alterius sit», se afirma que la misma es sospechosa, ya que no es exacto que el descubridor adquiera la cosa por ocupación: corresponde en su totalidad al descubridor, si es propietario del fundo; en otro caso, solamente la mitad. En su opinión, dicho argumento es rechazable: es verdad que la regulación jurídica post-adrianea ha reconocido al descubridor un derecho en los límites y en la forma indicada, pero la expresión del texto paulino puede igualmente defenderse argumentando de la circunstancia de que la adquisición es posible en cuanto, actualmente, no existe un propietario. Por qué esta afirmación puede ser escrita, en este sentido, por los compiladores y no puede, sin embargo, ser propia del jurista romano que escribe este texto.

Busacca, Qualche osservazione sulle innovazioni introdotte dai divi fratres nel regime giuridico del tesoro, cit., I48 nt. 50, afirma que las críticas vertidas sobre el texto no parecen convincentes, sobre todo, la atribución del tesoro según reglas diversas de aquellas adrianeas no pueden ser afirmadas para sostener la alteración de un texto escrito bajo el principado de Cómodo; la distinta configuración del tesoro respecto de las otras fuentes no puede ser apodícticamente atribuida a la intervención de los glosadores postclásicos o a los compiladores justinianeos, en cuanto que es muy diferente de aquella establecida en época postclásica y justinianea, en las que el tesoro no era considerado res nullius, a diferencia de lo que sucede en gran parte de la época clásica.

Redur 4 / 2006 
d) configuración de la adquisición por parte de terceros como furtum.

No menos conocido, es otro texto de Papiniano que recoge, explícita o implícitamente, los mismos requisitos que Paulo exige para la consideración jurídica del tesoro ${ }^{7}$.

D. 4I, 2, 44 pr. (Papinianus, XXXIII Quaestionum): Peregre profecturus pecuniam in terra custodiae causa condiderat: cum reversus locum thensauri immemoria non repeteret, an desisset pecuniam possidere, vel, si postea recognovisset locum, an confestim possidere inciperet, quaesitum est. Dixi, quoniam custodiae causa pecunia condita proponeretur, ius possessionis ei, qui condidisset, non videri peremptum, nec infirmitatem memoriae damnum adferre possessionis, quam alius non invasit: alioquin responsuros per momenta servorum, quos non viderimus, interire possessionem et nihil interest, pecuniam in meo an in alieno condidissem, cum, si alius in meo condidisset, non alias possiderem, quam si ipsius rei possessionem supra terram adeptus fuissem. Itaque nec alienus locus meam propriam aufert possessionem, cum, supra terram an infra terram possideam, nihil intersit.

El fragmento plantea el caso de una persona que al volver de viaje no recuerda el lugar donde ha enterrado una cantidad de dinero con finalidad de custodia. En esta situación, surge la duda de si ha dejado de poseer el dinero, o si habiendo reconocido después el lugar del ocultamiento comienza a poseer inmediatamente.

Papiniano, respecto del caso del dinero oculto con finalidad de custodia, declara que ya había respondido que no se extingue el ius possessionis, incluso en caso de una infirmitas memoriae, siempre que alguien no haya tomado posesión del dinero. Emblemática, como afirma Scarcella ${ }^{8}$, resulta la hipótesis de una apropiación del dinero limitada al caso de que de su ocultamiento viniese a faltar el recuerdo; en esta situación, según Paulo, existía un tesoro.

En lo que se refiere a nuestro tema, nos interesa ahora destacar que para Papiniano los requisitos que ha de reunir el tesoro son:

a) consistente en dinero;

b) ocultamiento en tierra;

c) falta de recuerdo del depósito;

7 Cfr. SCIALOJA, Teoria della proprietà nel diritto romano, II (Roma I933) 54, para quien Papiniano utiliza el término thesaurus en sentido no técnico.

8 SCARCELLA, Una nuova concezione del tesoro alla luce di C.I. IO.I5.I, cit., I95. La citada autora, op. cit. I95 nt. I5, rechaza la opinión de Mayer-Maly, Thensaurus meus, cit., 287 s., para quien el término thensaurus no es utilizado en sentido técnico. En su opinión, el citado fragmento fue redactado bajo el principado de Septimio Severo (cfr. FITTING, Alter und Folge der Schiften römischen ${ }^{\text {Juristen }}$ von Hadrian bis Alexander, cit., 73), por tanto, cuando ya con D. 4I, I, 3I, I (para la época de redacción de este fragmento cfr. FITTING, op. cit., 84) se había impuesto un uso correcto del término thensaurus. Además, en el fragmento de Papiniano concurren todos los requisitos exigidos por Paulo para la configuración jurídica del tesoro.

Redur 4 / 2006 
d) inexistencia del propietario 9 .

Veamos a continuación los diversos elementos que integran la definición de Paulo.

\section{I.I. Depositio pecunia.}

Un sector de la doctrina ${ }^{\mathrm{IO}}$, con base en C. Th. Iо, I8, 2 donde Teodosio I acumula pecunia y monilia, considera que el tesoro puede consistir tanto en dinero como en joyas o alhajas.

En nuestra opinión, dicha postura es fruto de esa tendencia que, partiendo del presupuesto de la existencia de un concepto unitario de tesoro válido para todas las épocas del Derecho romano, no tiene en cuenta, como afirma Scarcella ${ }^{\text {II }}$, la nueva realidad que surge como consecuencia de las transformaciones económico-sociales, el desarrollo del sistema crediticio y el fenómeno de la devaluación monetaria que tienen lugar a partir del comienzo del siglo III d.C. y que llevan a que se generalice la ocultación de monilia.

Otro sector doctrinal ${ }^{12}$ va incluso más lejos. Afirma, sin ninguna limitación cronológica, que el tesoro puede recaer sobre cualquier objeto mueble precioso, de valor. En apoyo de su tesis citan,

\footnotetext{
${ }^{9}$ Como afirma SCARCELLA, Una nuova concezione del tesoro alla luce di C.I. Io.I5.I, cit., I95 nt. I5, este requisito no es mencionado explícitamente por Papiniano, pero se puede fácilmente deducir de la hipótesis planteada por el propio jurista, de apropiarse de la pecunia por parte de quien la descubre.

Io LONGO, Corso di Diritto Romano. I diritti reali, cit., I05; FUENTESECA, Derecho Privado Romano (Madrid I978) IIo; PUGLIESE, Istituzioni di Diritto Romano (Torino I99I) 458; DI PIETRO, Derecho Privado Romano (Buenos Aires I996) I32; GUZMAN, Derecho Privado Romano, I (Chile I997) 540; VENTURA, Derecho Romano. Curso de Derecho Privado (México 2000) 210; SCHERILLO-GNOLI, Diritto Romano. Lezioni Istituzionali (Milano 2003) 362.

${ }^{\text {II }}$ SCARCELLA, Una nuova concezione del tesoro alla luce di C.I. IO.I5.I, cit., $200 \mathrm{~s}$.

I2 FUCHS, De thesauri acquisitione ex jure romano (Vratislaviae I87I) 7; DELLA PORTA, L'istituto giuridico dell'acquisto del tesoro. Dissertazione di Laurea (Torino I907) I3 S.; BUTERA, s.v. Tesoro, en D.I., 23 (I9I2-I9I6) 96I, 967; PACCHIONI, Corso di Diritto Romano, II (Torino I920) 383; MAYER-MALY, Thensaurus meus, cit., 283; VOLTERRA, Instituciones de Derecho Privado Romano, trad. esp. de Daza (Madrid I986) 332; TORRENT, Manual de Derecho Privado Romano (Zaragoza I987) 255; ARANGIO-RUIZ, Istituzioni di Diritto Romano (Napoli I994) I9I; BETANCOURT, Derecho Romano Clásico (Sevilla I995) 309; DALLA-LAMBERTINI, Istituzioni di Diritto Romano (Torino I996) 256; VOCI, Istituzioni di Diritto Romano (Milano I996) 273; DAZARODRÍGUEZ ENNES, Instituciones de Derecho Privado Romano (Madrid I997) I83; D' ORS, Derecho Privado Romano (Pamplona I997) 2II nt. 8; MARCHI, A «fanciulla d'Anzio» e o instituto do tesouro, en INDEX, 25 (I997) 369; ARGÜELLO, Manual de Derecho Romano (Buenos Aires I998) 230; GIMÉNEZ-CANDELA, Derecho Privado Romano (Valencia I999) I96; IGLESIAS, Derecho Romano (Barcelona I999) I68; DE LAS HERAS, Adquisición del tesoro en el Fuero de Cuenca: bases romanas y evolución posterior, en Actas del II Congreso Internacional y V Iberoamericano de Derecho Romano. Los derechos reales (Madrid 200I) 56 nt. I8, afirma que en todo caso, debe advertirse, máxime cuando nos referimos a un concepto de tesoro, en cuanto a su composición, más social que jurídico, y especialmente si lo situamos en época clásica, que el término pecunia puede significar también «riquezas»; SCAPINI, Manuale Elementare di Diritto Romano (Milano 2002) 208.
} 
D. 50, I6, I78 pr. (Ulpianus, XLIX ad Sabinum): Pecuniae verbum non solum numeratam pecuniam complecitur, verum omnem omnino pecuniam, hoc est omnia corpora; nam corpora quoque pecuniae appellatione contineri, nemo est, qui ambiget.

Ortega $^{\mathrm{I} 3}$ es quizá el autor que con más detenimiento ha tratado de justificar su posición. Refiriéndose a la hipótesis de Busacca de la existencia de una evolución en la que se habría pasado de un concepto más restringido del tesoro como dinero (pecunia), en el derecho clásico, a un concepto paulatinamente más amplio (monilia y mobilia), afirma que si interpretamos restrictivamente el término pecunia de la definición de Paulo, como dinero únicamente y excluyendo joyas $\mathrm{u}$ otros objetos de valor, también debemos interpretar rígidamente el texto de Graciano, Valentiniano y Teodosio, según el cual el tesoro estaría constituido sólo por joyas (monilia), excluyendo el dinero que C. Th. Io, I8, 2 no menciona. Y siguiendo la misma pauta, cuando Casiodoro (Variae 6, 8, 6), ya a principios del siglo VI, definía el tesoro como depositavae pecunia, deberíamos entender que el objeto del mismo estaría formado exclusivamente por dinero, excluyendo joyas u otros objetos de valor, aunque su intención no fuese más allá de aproximarse a la definición de Paulo. Según esto, la conclusión a que conduce una interpretación restrictiva de las fuentes, es cuanto menos singular e ilógica, y los resultados no acordes con la realidad práctica.

Añade el citado autor que causa extrañeza que Paulo, ya avanzado el siglo III d.C., en una época y en una sociedad ya evolucionada, con un complejo y activo tráfico jurídico, concibiese el tesoro como un depósito antiguo integrado exclusivamente por dinero. Creemos que la palabra pecunia de la definición del jurista debe ser entendida en sentido amplio, abarcando no sólo dinero o monedas propiamente dichas, sino también joyas o aderezos (monilia) o cualesquiera otros objetos de valor (mobilia). Máxime si tenemos en cuenta otro texto del mismo Paulo, extraído del libro segundo de sus comentarios al Edicto, y recogido en el De verborum significatione del Digesto:

D. 50, I6, 5 pr.: «Rei» apellatio latior est quam «pecuniae» quia etiam ea, quae extra computationem patrimonii nostri sunt, continet, cum pecuniae significatio ad ea referatur, quae in patrimonio sunt.

Observa que la significación de cosa es más lata que la de pecunia, pues comprende también lo que se halle fuera de nuestro patrimonio, en tanto que el significado de pecunia se refiere a lo que hay en el patrimonio. El término pecunia, pues, utilizado por Paulo en su definición de tesoro, tiene para el mismo jurista un significado más amplio que el de dinero o monedas, pues abarca todo aquello que puede encontrarse en nuestro patrimonio y, por tanto, con referencia al tesoro, pecunia sería cualquier objeto mueble precioso o, si se quiere valioso.

Otro texto que confirma esta interpretación es D. 50, I6, I78 pr. (Ulp. 49 ad Sab.). Texto que es interpretado por Ortega en el sentido que la palabra pecunia comprende no sólo el dinero contante, sino absolutamente todo valor, esto es, toda clase de cosas, pues no hay nadie que dude que las cosas -no genéricas- se comprenden también bajo la denominación de pecunia.

En otro texto, añade Ortega, D. 45, I, 50, I (Ulp.. 50 ad Ed.), el mismo jurista parte de una noción amplia de pecunia, identificando el vocablo con alguna cosa (cualquier cosa incluida en el caudal hereditario):

\footnotetext{
${ }^{\text {I3 }}$ ORTEGA, El concepto romano de tesoro y el artículo 352 del Código Civil, cit., 745 Ss.
} 
Item stipulatione emtae hereditatis: «quanta pecunia ad te pervenerit, dolove malo tuo factum est, eritve, quominus perveniat», nemo dubitabit, quin teneatur, qui id egit, ne quid ad se perveniret.

Concluye que de esta forma, el término pecunia de la definición de Paulo equivale plenamente a los hallazgos de cosas preciosas o de valor.

Por nuestra parte consideramos, como veremos a continuación, que no hay ninguna duda que la jurisprudencia clásica, incluido Paulo, otorga al término pecunia el significado técnico-jurídico de dinero, lo cual no supone ninguna interpretación restrictiva. Por otra parte, entendemos que en C. Th. Iо, I8, 2, Teodosio I regula junto al tesoro clásico (pecunia), también los monilia, asimilándolos bajo el mismo régimen jurídico cuando presentan una clara distinción conceptual, lo que debió de generar en la práctica gran confusión como ha demostrado Scarcella. Una tal interpretación del término pecunia por Paulo no nos parece ni singular ni ilógica, sino el fruto de la propia evolución históricojurídica del tesoro.

Acertada nos parece la interpretación de Marrone ${ }^{\mathrm{I} 4}$, que ha demostrado cómo la colocación de algunos pasajes en D. 50. I6 ha dado lugar a falsas generalizaciones. Probablemente los compiladores habrían (implícitamente) pensado que el intérprete habría sabido dar su justo alcance a la relativa significatio. Así sucede para términos de uso común, que habrían asumido en determinados contextos un significado técnico: interrumpido el nexo originario, se remitía a la perspicacia del intérprete y a su conocimiento de las fuentes establecer -tal vez restablecer- la conexión. Tal es el caso de pecunia, un término de época arcaica, adoptado en el ámbito jurídico, con acepciones amplias y diversas según el contexto, pero que asume tanto en el uso común como en el jurídico, el significado de dinero. Pues bien, los compiladores colocan en D. 50.16 algunos textos donde dan a pecunia, en términos generales y sin ninguna referencia a contextos particulares, un significado tan amplio que comprende ahora omnia corpora ( fr. 178 pr.).

Respecto a D. 50, I6, 5 pr., Marrone ${ }^{\mathrm{I} 5}$ afirma que el pasaje habría hecho referencia al vadimonium Romam faciendum; la amplia interpretación de res que se lee en el texto habría permitido utilizar el vadimonium también a aquellos que intentasen ejercitar acciones populares, actio iniuriarum, actio sepulchri violati, y similares.

Por lo que se refiere a D. 45, I, 50, I, consideramos que la acepción amplia de pecunia se encuentra limitada a un caso particular de stipulatio, sin que quepa extraer conclusión alguna para el tema del concepto de tesoro ${ }^{\mathrm{I} 6}$.

Para Puliatti ${ }^{17}$, la identificación del objeto del tesoro con la pecunia por parte del pensamiento jurídico clásico, es debido a que la tradición literaria anterior identifica el tesoro con aurum y con argentum.

I4 MARRONE, Nuove osservazioni su D. 50.16 «De verborum significatione», en Seminarios Complutenses de Derecho Romano, VII (Madrid i995) I69 ss., especialmente i82 s.

${ }^{15}$ MARRONE, Nuove osservazioni su D. 50. I6 «De verborum significatione», cit., I83 nt. 52.

${ }^{16}$ En este sentido, podríamos citar D. 50, I6, 97 (Celsus, XXXII Digestorum): Cum stipulamur «quanta pecunia ex hereditatis Titii ad te pervenerit» res ipsas, quae pervenerunt, non pretia earum spectare videmur. Cfr. MARRONE, Nuove osservazioni su D. 50. I6 «De verborum significatione», cit., I83 nt. 52. I69.

${ }^{\text {I7 }}$ PULIATTI, Il «de iure fisci» di Callistrato e il processo fiscale in età severiana )Milano I992) 
En nuestra opinión, Paulo acuña en su definición un concepto técnico-jurídico de tesoro frente al concepto vulgar como objeto de valor o precioso, por lo que con exacta precisión circunscribe el objeto del tesoro al dinero ${ }^{\mathrm{I} 8}$. Como afirma Scarcella ${ }^{\mathrm{I}}$, esta identificación no es una opinión personal de Paulo, sino que aparece en otros textos clásicos relativos al tesoro, incluso en una fuente literaria de época más antigua se identifica el objeto del descubrimiento con una cantidad de dinero.

D. 4I, 2, 44 pr. (Papinianus, XXIII Quaestionum): Peregre profecturus pecuniam in terra custodiae causa condiderat...

D. 48, I3, 4, 6 (Marcianus, XIV Institutionum): Non fit locus religiosus, ubi thesaurus invenitur; nam etsi in monumento inventus fuerit, non quasi religiosus tollitur; quod enim sepelire quis prohibetur, id religiosum facere non potest; at pecunia sepeliri non potest, ut et mandatis principalibus cavetur.

Plaut. Trinummus I77-I80

An ego alium dominum paterer fieri hisce aedibus?

Qui emisset, eius essetne ea pecunia?

Emi egomet potius aedis: argentum dedi

Thensauri causa, ut salvom amico traderem

Además, Teodosio I viene a confirmar esta interpretación cuando equipara monilia al thesaurus, equiparación que sólo se comprende partiendo de la base de una previa limitación conceptual del mismo al dinero ${ }^{20}$.

\section{I.2. Vetus depositio cuius non extat memoria.}

En general la doctrina romanística considera esencial la «depositio», es decir, que el tesoro se encuentre oculto ${ }^{2 \mathrm{I}}$, requisito puesto de relieve por Paulo con la expresión

${ }^{\text {I8 }}$ SCIALOJA, Teoria della proprietà nel diritto romano, II, cit., 48; MIQUEL, Derecho Privado Romano (Madrid I992) I94; GUZMAN, Derecho Privado Romano, cit., 54I; MARTINI, Appunti di Diritto Romano Privato (Padova 2000) 66; PANERO, Derecho Romano (Valencia 2000) 38I; MALAVÈ, «Pecunia, monilia y mobilia», como objeto del tesoro, en El derecho de familia y los derechos reales en la romanística española (I940-2000) (Huelva 2000) 45I; TALAMANCA, Elementi di Diritto Privato Romano (Milano 200I) 2I7; BRAVO GONZÁLEZ-BRAVO VALDÉS, Derecho Romano (México 200I) 2I3; MANFREDINI, Istituzioni di Diritto Romano (Torino 2003) I25.

${ }^{19}$ SCARCELLA, Una nuova concezione del tesoro alla luce di C.I. IO.I5.I, cit., I96.

${ }^{20}$ Como observa BUSACCA, s.v. Tesoro, cit., 388 nt. 77, distinta aparece la interpretatio visigótica a esta constitución, en la que se habla sólo de thesaurus, pero comprendiéndose tanto los objetos preciosos como la pecunia , como pone de relieve la siguiente frase: « si vero in loco alieno thesaurum casu invenerit eum, qui loci dominus est, in quartam inventarum rerum debet admittere ».

${ }^{21}$ FERRINI, Manuale di Pandette (Milano I900) 363, no considera la ocultación requisito necesario del tesoro.

Redur 4 / 2006 
«depositio pecuniae», que en opinión de Ortega ${ }^{22}$ designa tanto la acción de depositar como el mismo depósito o cosa depositada.

Dicho requisito se encuentra en el propio origen de la institución, pues como afirma Bonfante ${ }^{23}$, el verdadero tesoro, es decir, el esconder cantidades de dinero corresponde a una sociedad y a una economía primitiva, a una época en la que las guerras hacen necesario salvar la riqueza propia de manera extraordinaria; la misma ausencia de una organización del crédito que hiciera más segura la custodia de los capitales por parte de las entidades bancarias, explica la necesidad de esconderlos dentro de los muros o enterrarlos: el escondite era la caja fuerte. La casa antigua tenía, como el Estado, su tesoro.

Sin embargo, este requisito ha sido infravalorado por algunos autores. Bonfante ${ }^{24}$, partidario de mantenerlo como requisito, matiza que no se puede exigir que el objeto se encuentre en un lugar especifico realizado para tal fin, es suficiente con que no constituya parte o elemento natural del fundo. Tal es el caso de los objetos que se encuentran en lugares alejados o recónditos, in abdito loco; es decir, el supuesto contemplado en el texto de Trifonino ${ }^{25}$. Concluye con la afirmación de que en la práctica es poco probable que surjan discusiones acerca del ocultamiento.

Con esta posición Bonfante se acerca a aquellos autores que entienden que el ocultamiento no es un requisito del concepto de tesoro. Tal es el criterio de Ferrini ${ }^{26}$ cuando escribe que si se suele suponer que el tesoro fuese «escondido», es porque no se entiende de otro modo cómo haya podido permanecer ignorado por largo tiempo. Pero, en mi opinión, es tesoro, por ejemplo, la bolsa de monedas de oro que un alpinista pierde en una difícil escalada y que es encontrada un siglo después por quien se arriesga por los mismos precipicios, siempre que no quede memoria de aquel suceso, aunque las monedas hayan estado siempre al descubierto sobre el acantilado del monte.

Comparte este planteamiento Ortega ${ }^{27}$ cuando afirma que la ignorancia del depósito nos lleva a considerar si éste debiera estar oculto y, en su caso, si tal término deba considerarse en sentido amplio o estricto. A este respecto, el adjetivo oculto debe entenderse en sentido amplio, considerándose tesoro no sólo aquel depósito real y efectivamente «escondido» (invisible y cubierto), sino también aquellos objetos de valor, antiguos, que se encuentren sobre la superficie del suelo (no escondidos en sentido técnico), siempre que hayan permanecido ocultos a la vista de las gentes y de ellos no quede recuerdo alguno.

La importancia del ocultamiento ha sido puesta de relieve por Galgano ${ }^{28}$. Afirma este autor que no existe ninguna razón, desde el punto de vista jurídico, para otorgar un

${ }^{22}$ ORTEGA, El concepto romano de tesoro y el artículo 352 del Código Civil, cit., 740.

${ }^{23}$ BONFANTE, La vera data di un testo di Calpurnio Siculo e il concetto romano del tesoro, en Mélanges F. Girard, I (Paris I9I2 = Scritti giuridici vari, II: Proprietà e servitu (Torino I9I8) I39 ss.; Corso di Diritto Romano. La proprietà, II, 2, cit., I29 ss. En el mismo sentido, SCARCELLA, Una nuova concezione del tesoro alla luce di C.I. I0.I5.I, cit., I99.

${ }^{24}$ BONFANTE, La vera data di un testo di Calpurnio Siculo e il concetto romano del tesoro, cit., I4O s.; Corso di Diritto Romano. La proprietà, II, 2, cit., I4O. Igualmente, LONGO, Corso di Diritto Romano. I diritti reali, cit., I07.

${ }^{25}$ D. 4I, I, 63, 3 (Tryphoninus, VII Disputationum).

${ }^{26}$ FERRINI, Manuale di Pandette, cit., 363 nt. 2.

${ }^{27}$ ORTEGA, El concepto romano de tesoro y el artículo 352 del Código Civil, cit., 744 s.

${ }^{28}$ GALGANO, Dell'acquisto del tesoro e del requisito del nascondimento nella tradizione storica e nel diritto vigente, en Il Filangieri. Rivista giuridica, dottrinale e pratica, 33 (I908) I4 SS.

Redur 4 / 2006 
tratamiento distinto a las cosas abandonadas o nullius de aquellas de valor que se encuentren ocultas. En efecto, éstas pueden haber sido enterradas por las personas más diversas: propietario, depositario, e incluso por un ladrón; y pueden encontrarse en las condiciones jurídicas más variadas: nullius o cosas que pueden tener un propietario. Pero si lógicamente no era necesario hacer para ellas una categoría especial, el hecho es que tal categoría existe, y si existe debe de haber alguna razón que impulsó a su creación. Y tal razón, por lo que se ha dicho, parece que debe derivar de la especial condición del ocultamiento. Concluye que el ocultamiento es el único elemento que permite diferenciar entre las cosas abandonadas y nullius que se encuentran en la superficie del suelo de modo visible a todos, y el tesoro que sin embargo se encuentra oculto y no visible.

No nos cabe duda que el ocultamiento es un requisito esencial del concepto de tesoro, pero entendido como hacen los juristas romanos en el sentido de enterramiento.

Galgano $^{29}$, cita un texto de Pomponio donde destaca la idea del enterramiento:

D. IO, 4, I5 (Pomponius, XVIII ad Sabinum): Thesaurus meus in tuo fundo est, nec eum pateris me effodere...

Para Puliatti ${ }^{30}$, Paulo considera todavía el enterramiento como un requisito esencial para la existencia jurídica del tesoro:

D. 4I, 2, 3, 3 (Paulus, LIV ad Edictum):.....Ideoque si thensaurum in fundo meo positum sciam continuo me possidere, simul atque possidendi affectum habuero....,

igualmente Papiniano, que se pronuncia como hemos visto sobre los mismos requisitos que Paulo exige para la configuración jurídica del tesoro, y destaca el ocultamiento en tierra:

D. 4I, 2, 44 pr. (Papinianus, XXXIII Quaestionum)3r. Peregre profecturus pecuniam in terra custodiae causa condiderat [....]. Itaque nec alienus locus meam propiam aufert possessionem, cum supra terram an infra terram possideam, nihil intersit,

en idéntico sentido se expresa Ulpiano que cita la opinión de Labeón:

D. IO, 2, 22 pr. (Ulpianus, XIX ad Edictum): Item Labeo scribit, si unus heredum thesaurum relictum a testatore effodit...32

${ }^{29}$ GALGANO, Dell'acquisto del tesoro e del requisito del nascondimento nella tradizione storica e nel diritto vigente, cit., 3I. Cfr. MAYER-MALY, Thensaurus meus, cit., 285 s., que considera no técnico el uso del término tesoro.

${ }^{30}$ PULIATTI, Il «de iure fisci» di Callistrato e il processo fiscale in età severiana, cit., I68 nt. 57.

${ }^{3}$ El verbo «condere» es utilizado raramente por los juristas. Vid. CASAVOLA, Scienza, potere imperiale, ordinamento giuridico nei giuristi del II secolo, en IURA, 27 (I976) I8 nt. 3 = Giuristi Adrianei (Napoli i980) I66.

${ }^{2}$ Cfr. MAYER-MALY, Thensaurus meus, cit., 288, para quien el término «thesaurum» no es utilizado en sentido técnico.

Redur 4 / 2006 
Afirmado el principio que el tesoro debe estar enterrado, surge la pregunta de si dicho enterramiento se refiere al momento inicial cuando se realiza el depósito, o al momento del descubrimiento. Es cierto que los participios no tienen tiempo, la expresión «cosa enterrada» puede aludir tanto al tiempo pasado como al tiempo presente, pero descartado, como veremos a continuación, que el Derecho romano exigiera la voluntariedad del ocultamiento, conviene decidirse por la segunda opción, ya que cuando el objeto, enterrado, se hace visible por alguna fuerza natural o humana, no se puede hablar de descubrimiento y, por tanto, pierde su consideración de tesoro.

Hasta ahora hemos visto que los textos hablan siempre de hallazgos enterrados sobre fundos, pero la doctrina romanística se plantea la cuestión de si podríamos considerar tesoro, desde el punto de vista jurídico, el descubrimiento realizado sobre una cosa mueble.

Perozzi ${ }^{33}$ afirma que no hay ninguna razón para otorgar un tratamiento jurídico distinto al tesoro descubierto en un inmueble del que lo sea en un mueble.

En la misma línea, Bonfante ${ }^{34}$ escribe que ni Paulo ni León ni otros exigen como requisito la inmovilidad del objeto en el que el tesoro es descubierto. Es verdad que los textos aluden a tesoros descubiertos sub terra, in terrulis, e incluso en una domus ${ }^{35}$, pero extraer de ello un requisito del tesoro es como querer extraer un requisito parecido de los casos prácticos que a nuestra jurisprudencia se presentan, los cuales también conciernen a fundos y no a cosas muebles.

En términos parecidos, Ortega y Lozano $^{36}$ afirman que dado que las fuentes silencian este extremo, y no encontrándose ninguna decisión jurisprudencial en contra, creemos que se debe optar por la solución más amplia, esto es, la irrelevancia jurídica del lugar donde el descubrimiento se efectúe.

Posteriormente Ortega ${ }^{37}$ ha reiterado esta idea afirmando que si bien es verdad que, en la práctica serán más frecuentes los hallazgos efectuados bajo tierra o entre los muros de alguna vivienda, que aquellos descubiertos en los cajones de una vieja cómoda o en el compartimento secreto de un escritorio, por ejemplo, nada se opone a que tanto uno como otro sean calificados como tesoro, siempre que concurran los restantes requisitos.

En nuestra opinión, el argumento ex silentio no puede considerarse como prueba; sí lo es, en cambio, la idea de enterramiento y de inherencia del tesoro al fundo que viene a constituir una tradición ininterrumpida durante toda la vida de la institución del tesoro en

33 PEROZZI, Contro l'istituto giuridico dell'acquisto del tesoro, en Monitore dei tribunale, 3I (I890) = Scritti giuridici, I (Milano I948) 293. Igualmente, DELLA PORTA, L'istituto giuridico dell'acquisto del tesoro, cit., I8; BUTERA, s.v. Tesoro, cit., 970 s.; PACCHIONI, Corso di Diritto Romano, II, cit., 383; BRAVO GONZÁLEZ-BRAVO VALDÉS, Derecho Romano, cit., 2I3;

34 BONFANTE, Corso di Diritto Romano. La proprietà, II, 2, cit., I42.

${ }^{35}$ D. 6, I, 67 (Scaevola, I Responsorum): A tutore pupilli domum mercatus ad eius refectionem fabrum induxit, is pecuniam invenit; quaeritur, ad quem pertineat? Respondi, si non thesauri fuerunt, sed pecunia forte perdita, vel per errorem ab eo, ad quem pertinebat, non ablata, nihilo minus eius eam esse, cuius fuerat.

Cfr. SCIALOJA, Teoria della proprietà nel diritto romano, II, cit., 57; LONGO, Corso di Diritto Romano. I diritti reali, cit., I07, afirman que el texto no dice si el dinero encontrado es o no tesoro, ni tampoco si ha sido descubierto en un mueble o en el inmueble mismo; luego nada se puede extraer del citado texto, ni a favor ni en contra.

${ }^{36}$ ORTEGA, Derecho Privado Romano, cit., I64; LOZANO, Historia e Instituciones de Derecho Romano, cit., 383.

37 ORTEGA, El concepto romano de tesoro y el artículo 352 del Código Civil, cit., 745. 
el Derecho romano ${ }^{38}$. En cualquier caso, ante el silencio de las fuentes, la discusión y la resolución de la controversia están abiertas.

Dentro de la doctrina mayoritaria que exige el requisito del ocultamiento, se discute si el inicial ocultamiento debe ser voluntario o hecho por la mano del hombre, o bien involuntario o por acción de las fuerzas de la naturaleza.

Algunos autores, con base en la terminología utilizada por las fuentes para referirse al tesoro, consideran que quedan fuera del concepto de tesoro aquellas cosas que no fueron escondidas por la mano del hombre. Así, Perozzi ${ }^{39}$, apoyándose en el propio término depositio utilizado por Paulo, considera que los romanos quieren destacar que el objeto del tesoro haya sido ocultado por alguien y no simplemente que haya permanecido oculto. Añade que cuando el término oculto, en lugar de ser utilizado como adjetivo que alude a una condición del objeto, es utilizado como participio, aquella condición resulta ser el fruto de una actividad humana. Ocultar, por tanto, no significa únicamente esconder una cosa, sino realizar un acto dirigido a imposibilitar su localización. En este sentido, quien esconde una cosa con una finalidad distinta a la de impedir su localización, no esconde en el sentido jurídico del término.

Para Bonfante ${ }^{40}$ también las fuentes romanas parecen aludir al carácter voluntario del depósito. El término depositio supone un acto del propietario dirigido a ocultar el tesoro. Sin embargo, los jurisconsultos romanos no pensaron en la necesidad de que debía probarse que el tesoro hubiera sido escondido voluntariamente. La pecunia condita era en origen el verdadero tesoro: los descubrimientos arqueológicos, que constituyen el caso más frecuente de tesoro moderno, eran casi extraños al mundo antiguo o al menos al mundo clásico. Uno de los casos más típico de descubrimiento arqueológico, es decir, la apertura y expolio de sepulturas antiguas, podía incurrir en la antigüedad bajo la sanción penal de la actio sepulchri violati, que era popularis, esto es, competía en ausencia de los interesados próximos a cuivis de populo.

Por el contrario, en opinión de Galgano $^{4 \mathrm{I}}$ la voluntariedad del depósito se encuentra con el inconveniente casi insalvable de la dificultad de su prueba: ¿cómo probar, salvo en casos muy limitados, que el ocultamiento es obra del hombre? ¿Cómo probar que el lugar donde ha sido descubierto el tesoro es el mismo donde fue ocultado? Y en el caso de que como consecuencia de un corrimiento de tierras el tesoro haya sido transportado a otro lugar, ¿se puede considerar el ocultamiento obra de la naturaleza? Si el tesoro descubierto corresponde la mitad al inventor y la mitad al dominus loci, ¿se modificará dicha participación si el ocultamiento es obra de la naturaleza? Por todas estas razones, la posición de aquellos autores que limitan el concepto de ocultamiento a la mano del hombre es inaceptable. Ocultamiento involuntario o voluntario, el tesoro es siempre el mismo.

\footnotetext{
${ }^{8}$ Así, SCIALOJA, Teoria della proprietà nel diritto romano, II, cit., 56 s.; PULIATTI, Il «de iure fisci» di Callistrato e il processo fiscale in età severiana, cit., I68 s.; BETANCOURT, Derecho Romano Clásico, cit., 309; GIMÉNEZ-CANDELA, Derecho Privado Romano, cit., I96

39 PEROZZI, Tra la fanciulla d'Anzio e la Niobide, cit., 257 s., 262.

$4^{\circ}$ BONFANTE, Corso di Diritto Romano. La proprietà, II, 2, cit., I4O s. En el mismo sentido, LONGO, Corso di Diritto Romano. I diritti reali, cit., IO7.

${ }^{4}$ I GALGANO, Dell'acquisto del tesoro e del requisito del nascondimento nella tradizione storica e nel diritto vigente, cit., I6. Igualmente, DELLA PORTA, L' istituto giuridico dell' acquisto del tesoro, cit., $18 \mathrm{~s}$.
}

Redur $4 / 2006$ 
De manera parecida se expresan Ortega y Lozano ${ }^{42}$ cuando afirman que el término depositio no indica voluntariedad, sino que es indiferente que el escondite se deba a la voluntad humana o a la casualidad. Ortega ${ }^{43}$ añade que la expresión depositio es poco afortunada y debe interpretarse en sentido amplio entendida como descriptiva e ilustrativa, pero no en sentido estricto ni como limitativa. Lo entenderemos mejor con algún ejemplo: supongamos que como consecuencia de un movimiento sísmico quedan sepultadas varias viviendas con todos sus enseres, incluido un cofre con joyas y monedas, descubriéndose mucho tiempo después; en este caso el escondite es debido a la casualidad y, sin embargo, el hallazgo no dejará de ser considerado tesoro. Además constituyendo dos de los requisitos del tesoro la inexistencia del propietario y el no quedar memoria del mismo, sería muy difícil dictaminar si el depósito encontrado fue escondido voluntariamente o no.

En nuestra opinión, no hay duda que Paulo al utilizar el término depositio quiere destacar la voluntariedad del ocultamiento en el momento inicial en el que el hombre oculta las monedas con finalidad de custodia o de conservación. Sin embargo, si contemplamos la cuestión desde el punto de vista del descubrimiento, no les falta razón a aquellos autores que objetan su prueba. Habrá tesoro siempre que concurran en el momento del hallazgo los requisitos exigidos por Paulo, siendo irrelevante que el inicial ocultamiento hay sido voluntario o hecho por la mano del hombre, o que las monedas abandonadas o perdidas hayan quedado ocultadas involuntariamente o por acción de las fuerzas de la naturaleza. Paulo no exige al descubridor que pruebe la voluntariedad del inicial ocultamiento.

Lo mismo cabe afirmar respecto de la necesidad de que el ocultamiento lo realice el propietario. Para Butera ${ }^{44}$, si no se conoce ni se debe conocer al propietario, no se puede exigir que sea él quien realice el depósito; habrá tesoro, si se dan los requisitos para ello, con independencia de quien fue la persona que llevó a cabo el depósito, incluso aunque no tenga ningún derecho sobre la cosa. En opinión de Bonfante ${ }^{45}$, los juristas romanos nunca se plantearon esta cuestión y, por tanto, no hay ningún texto donde se exija este requisito. Para Longo ${ }^{46}$, este requisito no se puede afirmar ni en sentido positivo ni en sentido negativo para todas las épocas, para el derecho clásico, su deducción del texto de Paulo resultaría arbitraria, dado que guarda silencio. memoria».

Para Paulo, tesoro es un «antiguo» depósito de monedas, «del que no queda

Afirma Ortega ${ }^{47}$ que de las fuentes puede conjeturarse la enorme importancia que el Derecho romano atribuía al elemento de la antigüedad; pero como, al tratar de argumentarlo surge ineludiblemente la relación causa-consecuencia con aquel otro de la falta de propietario, la doctrina ha supervalorado este último en detrimento de aquél que nos ocupa (la antigüedad).

La antigüedad del depósito ha sido rechazada por Perozzi ${ }^{48}$ en conexión con el requisito de la inhallabilidad del propietario. El citado autor niega el primer requisito,

\footnotetext{
$4^{2}$ ORTEGA, Derecho Privado Romano, cit., I63 s.; LOZANO, Historia e Instituciones de Derecho Romano, cit., 383 .

${ }^{43}$ ORTEGA, El concepto romano de tesoro y el artículo 352 del Código Civil, cit., $740 \mathrm{~s}$.

${ }^{44}$ BUTERA, s.v. Tesoro, cit., 967.

${ }^{45}$ BONFANTE, Corso di Diritto Romano. La proprietà, II, 2, cit., I4I.

${ }^{46}$ LONGO, Corso di Diritto Romano. I diritti reali, cit., I07.

47 ORTEGA, El concepto romano de tesoro y el artículo 352 del Código Civil, cit., 74I.

${ }^{4}$ PEROZZI, Tra la fanciulla d'Anzio e la Niobide, cit., 259 ss.
} 
reconoce el segundo, pero lo critica por cuanto que es entendido habitualmente como la base del instituto jurídico del tesoro, cuando en su opinión éste debería formar parte del régimen de las cosas abandonadas. El requisito de la inhallabilidad del propietario se suele vincular con la antigüedad como la consecuencia a su causa. Rechazado el requisito de la antigüedad, puesto que no tiene sentido, Perozzi critica especialmente la fórmula que los vincula, en cuanto que parece justificar que existe una antigüedad suficiente como para producir la inhallabilidad. A pesar de ello, reconoce que cuanto más antiguo sea el depósito, menos probabilidades hay de poder determinar su propietario actual. Añade que, no obstante, nunca pueden reducirse a cero, a aquel cero que sería necesario para poder concluir que la inhallabilidad es consecuencia de la antigüedad, únicamente tendríamos dicha certeza en los depósitos que se remonten a tiempos prehistóricos. Por ello, considera que el único elemento esencial del tesoro es la ausencia del propietario; la antigüedad del depósito únicamente es mencionada como una de las circunstancias más frecuentes que pueden conducir a pensar en la inhallabilidad del propietario. Para justificar su posición propone el siguiente ejemplo de tesoro reciente: una moneda con la efigie del monarca actualmente reinante encontrada entre las ruinas de un teatro que se incendió hace seis meses sería tesoro porque es un objeto mueble de valor, escondido, del que es seguro que nadie podrá probar que lo encontrado sea lo que él ha perdido y no lo que pudo haber perdido cualquiera de los otros miles de espectadores que huyeron del incendio. Con este planteamiento, Perozzi considera acertada la posición de aquellos autores como Maynz, y en el fondo también Keller, que suprimen el requisito de la antigüedad en sus definiciones del tesoro.

Por su parte, Voci ${ }^{49}$ considera que la antigüedad no puede entenderse como requisito jurídico, constituyendo sólo un elemento válido, en vía de hecho, como presupuesto de la falta de propietario.

En esta línea se encuentran Ortega y Lozano ${ }^{50}$ cuando escriben que a primera vista pudiera parecer que la antigüedad es un requisito indispensable para que un hallazgo sea calificado de tesoro. Sin embargo la antigüedad es relativa y condicionada a la inexistencia del propietario, del mismo modo que la vecindad no es requisito de las servidumbres prediales, sino que también es relativa y condicionada a la posibilidad de su ejercicio. De la misma forma que lo importante en las servidumbres prediales es que el ejercicio de la servidumbre sea posible, siendo irrelevante la distancia entre los fundos, para que un hallazgo pueda considerarse tesoro, el elemento esencial se concreta en la inexistencia del dueño, siendo irrelevante que el depósito sea más o menos antiguo. Al hilo de este planteamiento podríamos concretar: -el depósito tendrá la suficiente antigüedad para que no exista su dueño; -cuanto más antiguo sea menos posibilidades habrá de que su dueño exista.

Ortega $^{5 \mathrm{I}}$, en un estudio posterior reitera que la definición de Paulo alude expresamente a la antigüedad (vetus). Ahora bien, la antigüedad es un elemento importante a la hora de elaborar un concepto de tesoro, pero no debemos considerarla un requisito esencial del mismo. En la ecuación antigüedad-inexistencia o inhallabilidad del propietario, la antigüedad depende mucho más de la inexistencia del propietario que viceversa, la prueba es que un hallazgo, por muy antiguo que fuese, si se conoce su dueño (heredero del primitivo), no es considerado tesoro desde el punto de vista jurídico, aunque sí en el sentido amplio y vulgar del término; en todo caso, y ahí su relevancia, las posibilidades de existencia del dueño decrecen a medida que se incremente la antigüedad del depósito. Así las cosas,

\footnotetext{
${ }^{49}$ VOCI, Modi di acquisto della proprietà, cit., 24.

$5^{\circ}$ ORTEGA, Derecho Privado Romano, cit., I63; LOZANO, Historia e Instituciones de Derecho Romano, cit., 382 s. Igualmente, PANERO, Derecho Romano, cit., 38I.

${ }^{51}$ ORTEGA, El concepto romano de tesoro y el artículo 352 del Código Civil, cit., 74I ss.
} 
no queriendo restar importancia a la antigüedad y estimando, al mismo tiempo, que no debe ser considerada como requisito esencial del concepto de tesoro, podríamos calificarla de cuasi-requisito (como si fuese un requisito, que no lo es exactamente), utilizando la socorrida ambigüedad romana de los cuasi-contratos.

Añade el citado autor ${ }^{52}$ que ahora solo cabría preguntarse si es deseable y, en su caso, factible, establecer la magnitud de la antigüedad necesaria a partir de un límite, y fijando un mínimo número de años por encima del cual se podría calificar el hallazgo de tesoro. No lo creemos ni factible ni deseable, pues estamos ante una quaestio facti que impone remitirse, caso por caso, a una antigüedad tal que pueda razonablemente presumirse que no aparecerá un hipotético propietario, una antigüedad tal que quiebre toda esperanza de poder averiguar quién sea su dueño.

Acertadamente Bonfante ${ }^{53}$, en respuesta a la posición de Perozzi, considera que es erróneo no el requisito de la antigüedad, sino la inhallabilidad del propietario que lleva a suprimir el primer requisito. Las fuentes con una unanimidad ciertamente extraña y de manera reiterada expresan una idea precisa y profundamente distinta: no la ignorancia, sino la ausencia de propietario: el tesoro no tiene un dominus: ut iam dominium non habeat; quod non alterius sit; pecuniae quae...competentes dominos amisserunt. En su opinión, el concepto de las fuentes no sólo es claro, sino que es el único que permite distinguir el tesoro de las cosas abandonadas, perdidas o depositadas hace poco tiempo de propietario desconocido. El propietario del tesoro no es simplemente inhallable, sino inexistente. Desde este punto de vista, el requisito de la antigüedad cobra todo su valor, es verdaderamente la causa por la que el objeto se puede considerar que ha perdido su propietario. Si el depósito es reciente, el propietario puede ser inhallable, pero es casi seguro que hay un propietario $y$, por tanto, el objeto debe tratarse como una cosa abandonada.

Paulo exige además que «no quede memoria del depósito».

Perozzi ${ }^{54}$ distingue entre la antigüedad del depósito y la falta de memoria sobre el mismo. Afirma que la inmemorialidad no significa, tratándose de tesoro, que éste sea antiguo, la memoria de un depósito puede cesar al día siguiente a aquél en que fue hecho con la vida de quien hizo secretamente el depósito. En cambio, puede perfectamente conservarse la memoria del depósito entre la gente y ser éste antiquísimo; los recuerdos sobre los tesoros son, en efecto, tenacísimos. Por tanto, la antigüedad del depósito y la memoria de los hombres no están en ninguna relación de causa a efecto.

Ortega ${ }^{55}$ ha observado a la posición de Perozzi que tal planteamiento no es del todo admisible, pues, entre otras cosas, constituye un genuino ejemplo de sofisma. En efecto, si un tal muere apenas escondidas cosas de valor, indudablemente el depósito será ignorado y no antiguo, pero por ignorado no será descubierto, y a la larga terminará convertido en un depósito antiguo, y será más bien la antigüedad y no la ignorancia del depósito la causa de la falta de dueño; en el segundo caso, si de verdad las gentes hubiesen guardado, no cualquier memoria, sino una memoria exacta, no sólo de la existencia, sino también del lugar donde fue escondido el tesoro, cuánto ha que lo hubiesen descubierto en propio beneficio: la memoria a la que se refiere Perozzi es vaga, nebulosa e imprecisa sobre la

$5^{2}$ ORTEGA, El concepto romano de tesoro y el artículo 352 del Código Civil, cit., 743.

53 BONFANTE, La vera data di un testo di Calpurnio Siculo e il concetto romano del tesoro, cit., I32 s.; Corso di Diritto Romano. La proprietà, II, 2, cit., I43 ss. En el mismo sentido, LONGO, Corso di Diritto Romano. I diritti reali, cit., Io6

54 PEROZZI, Contro l'istituto giuridico dell'acquisto del tesoro, cit., $297 \mathrm{ss}$.

${ }^{55}$ ORTEGA, El concepto romano de tesoro y el artículo 352 del Código Civil, cit., 744.

Redur 4 / 2006 
existencia misma del tesoro, y totalmente errada e incorrecta sobre el lugar en que el mismo se encontraría escondido.

En nuestra opinión, es erróneo considerar de manera distinta la inmemorialidad y la antigüedad, entendemos que Paulo viene a hacer sinónimo la idea de que no quede memoria del depósito con la de la antigüedad del mismo. En este sentido ha de interpretarse el final del texto de Paulo cuando afirma no ser tesoro lo enterrado recientemente vel lucri causa vel metus vel custodiae pues probablemente existirá un dominus.

Desde esta perspectiva, afirma Scarcella ${ }^{56}$ que Paulo con la expresión «...vetus quaedam depositio pecuniae, cuius non exstat memoria...» ha querido referirse a un ocultamiento que puede considerarse «vetus» en cuanto que no existe ningún recuerdo, en otras palabras, el atributo «vetus» cualifica la depositio en íntima conexión con la inmemorialidad. Añade la citada autora que si ya es difícil, cuando se descubre un tesoro, determinar quién es el propietario, dicha dificultad aumenta si el tesoro es una cantidad de dinero oculta desde tiempo tan antiguo que nadie conserva recuerdo alguno; sólo a través de documentos o de personas que conociesen al autor del ocultamiento se podría probar la condición de propietario. Por otra parte, la pecunia permite de manera aproximada establecer la época de su acuñación; no obstante, saber cuando el dinero ha sido acuñado no significa poder fijar con precisión la época del ocultamiento, sobre todo si la acuñación pertenece a tiempos muy remotos, pero dicha acuñación también puede ser reciente y, en este caso, existirá la certeza de estar frente a un ocultamiento relativamente antiguo. Concluye que esta posibilidad de descubrir una cantidad de dinero oculta recientemente debe haber sido considerada por Paulo, ya que define el tesoro como una «depositio pecuniae», no antiquísima, sino sólo tan antigua que no quede recuerdo.

Recientemente Bussaca ${ }^{57}$ ha interpretado el requisito de «no quede memoria del depósito» como depósito escondido desde tiempo inmemorial, añadiendo que de este elemento desciende la ausencia de la falta de un dueño.

Ortega $^{58}$ ha objetado a la posición de Bussaca que la ignorancia del depósito debe ponerse en relación con la antigüedad y no con la falta de propietario: el propietario no existe porque, fundamentalmente, el depósito es antiguo y, a su vez, el depósito es ignorado porque es antiguo, pero no viceversa. Así, la antigüedad del depósito será generalmente la causa de que no pueda recordarse el mismo, y ambos elementos, antigüedad e ignorancia del depósito, conforman a su vez, el presupuesto propicio de la inexistencia del propietario, constituyendo indicios más que razonables para que el dueño falte.

\section{I.3. Depositio ut iam dominium non habeat.}

Paulo exige que «el depósito no tenga dueño».

Pacchioni ${ }^{59}$ afirma que el tesoro no es, según el concepto romano, una res nullius, y no lo es porque no se considera abandonada, sino sólo depositada por quien fue su

${ }^{56}$ SCARCELLA, Una nuova concezione del tesoro alla luce di C.I. IO.I5.I, cit., I94 Ss.

${ }^{57}$ BUSSACA, s.v. Tesoro, cit., 388.

$5^{8}$ ORTEGA, El concepto romano de tesoro y el artículo 352 del Código Civil, cit., 744.

59 PACCHIONI, Corso di Diritto Romano, II, cit., 383 ss. En el mismo sentido, BUTERA, s.v. Tesoro, cit., 975 s.; D' ORGEVAL, L'Empereur Hadrien. Oeuvre législative et administrative (Paris I950) I08; MIQUEL, Derecho Privado Romano, cit., I94; PANERO, Derecho Romano, cit., 38I nt. I8.

Redur 4 / 2006 
propietario. No es una res derelictae, es una cosa depositada de la que no se puede afirmar su propietario, pero que viene considerada como si no tuviera dueño, por la casi certeza de que el propietario no aparecerá. El tesoro no es, en sentido estricto, una res nullius, sino quasi-nullius. La adquisición no es definitiva, sino subordinada a la condición de que el originario propietario no aparezca y demuestre su derecho.

Esta idea ha sido rebatida con acierto por Bonfante ${ }^{60}$ cuando afirma que nadie niega que el tesoro sea una cosa depositada, no abandonada: si fuese res derelicta no se podría hablar del instituto del tesoro. Pero la cosa depositada no deviene tesoro sino cuando ha desaparecido el propietario o sus herederos. Analizada la definición de Paulo, la definición y las noticias administrativas de Casiodoro y de Constantino, la historia descrita por el texto de Calpurnio Sículo y finalmente los argumentos prácticos y dogmáticos, se puede concluir que al menos todos hablan de inexistencia y no de inhallabilidad. Reitera el citado autor que las fuentes de manera permanente afirman que el tesoro no tiene un dominus: ut iam dominum non habeat; quod non alterius sit; pecuniae quae...competentes dominos amiserunt. Ningún autor ha tomado estas expresiones literalmente, ya que considerar el tesoro como una verdadera res nullius les ha parecido a todos absurdo; y como tal absurdo (Unsinen) Beseler propone suprimir la frase de la definición de Paulo. Insiste el citado autor que el tesoro es una res sine domino, sine herede, una verdadera res nullius de naturaleza especial, que ha quedado como tal por la extinción del propietario y de sus sucesores. Es el fisco quien, con sus pretensiones sobre los bienes vacantes, ha contribuido a dar relieve a la figura del tesoro, que se puede incluir entre los bienes sine domino, sine herede, sine successore: situación que deviene específica y técnica. Para Bonfante la antigüedad es la causa por la que se puede considerar que el objeto ha perdido su propietario.

En términos parecidos, Scarcella ${ }^{6 \mathrm{I}}$ afirma que el hecho de que no exista recuerdo del ocultamiento no solo prueba la vetustas de la depositio, sino también la imposibilidad de probar la existencia de un derecho de propiedad sobre la pecunia descubierta; si nadie puede probar su condición de propietario, se puede hablar de un propietario inexistente.

También Ortega ${ }^{62}$ prefiere hablar de inexistencia antes que de inhallabilidad. Y esta elección no es caprichosa ni arbitraria, pues el texto es taxativo: el propietario de aquel depósito oculto e ignorado, no es simplemente inhallable, sino inexistente (no tiene dueño). También Casiodoro dice competentes dominos amiserunt, concibiendo el tesoro como una cosa que ha perdido a su propietario. De manera que quizá sea más preciso hablar de inexistencia que de inhallabilidad. La inexistencia del propietario alude a una situación definitiva, la inhallabilidad apunta a una situación condicionada: que el propietario no se encuentre en un momento determinado, no quiere decir que no pueda ser hallado más adelante, por lo que faltaría título de adquisición.

Ahora bien, si es requisito que el depósito no tenga dueño, ¿qué ocurre cuando éste aparece, hay tesoro? ¿puede reivindicarlo?

${ }^{60}$ BONFANTE, Corso di Diritto Romano. La proprietà, II, 2, cit., I44 SS. En el mismo sentido, DELLA PORTA, L'istituto giuridico dell'acquisto del tesoro, cit., I9 ss.; FUENTESECA, Derecho Privado Romano, cit., IIo; ARIAS RAMOS-ARIAS BONET, Derecho Romano, I (Madrid I979) 240; DAZA-RODRÍGUEZ ENNES, Instituciones de Derecho Privado Romano, cit., I83; IGLESIAS, Derecho Romano, cit., I68; MARTINI, Appunti di Diritto Romano Privato, cit., 66; TALAMANCA, Elementi di Diritto Privato Romano, cit., 2I7; BRAVO GONZÁLEZ-BRAVO VALDÉS, Derecho Romano, cit., 2I3;

${ }^{6 I}$ SCARCELLA, Una nuova concezione del tesoro alla luce di C.I. IO.I5.I, cit., I94, 203.

${ }^{62}$ ORTEGA, El concepto romano de tesoro y el artículo 352 del Código Civil, cit., 748 s. 
Para Pacchioni esta claro, la adquisición no es definitiva, sino subordinada a que el originario propietario no aparezca y demuestre su derecho. Esta interpretación, sin embargo, presenta el inconveniente de que las fuentes romanas parecen abogar con claridad a favor de la inmediata y definitiva adquisición del tesoro por su inventor y/o el dominus loci y en contra, por tanto, de una adquisición provisional del mismo. Por otra parte, resulta contradictorio y discriminatorio admitir la adquisición del tesoro como un modo de adquisición de la propiedad y a su vez sostener su reivindicabilidad, ello conduce en realidad a negar que existe un modo de adquirir la propiedad denominado tesoro, y a tratarlo de cara a sus efectos adquisitivos de manera discriminatoria respecto de otros modos de adquisición, como por ejemplo la ocupación.

En el polo opuesto, pero bajo la misma idea de adquisición revocable, se sitúan Ortega y Lozano $^{63}$ cuando escriben que desde luego, si el propietario es hallado, el descubrimiento deja automáticamente de ser tesoro.

Perozzi $^{64}$, que como hemos visto critica el binomio antigüedad del depósitoinhallabilidad del propietario, se sorprende de que la doctrina admita la reivindicación del tesoro. Esta unanimidad, observa el autor, impresiona por el hecho de que los autores razonan al filo de la lógica, pero hay una lógica jurídica que destruye la fuerza del argumento meramente dialéctico con el que se razona. La ley admite un caso de adquisición del dominio, al que le faltan los requisitos lógicos de toda adquisición del dominio, los cuales deben estar fijados en el momento de la adquisición. Quienes sostienen la opinión de que la adquisición es revocable, eliminan este modo de adquisición que se denomina tesoro. Perozzi, que caracteriza el tesoro como cosa oculta de dueño inhallable a la vista de las circunstancias del descubrimiento, niega la reivindicabilidad del tesoro. Con esta posición Perozzi supera las objeciones de la tesis de Pacchioni, pero se enfrenta a otra de difícil justificación: ¿cómo impedir que el propietario del objeto descubierto pueda reclamarlo?

Más acertada nos parece la opinión de Bonfante $^{65}$ que, como hemos visto, partiendo no de la inhallabilidad sino de la inexistencia del propietario, afirma que si el propietario se presenta y prueba su derecho, ello supone que la cosa no era sine domino, no era tesoro. No es en absoluto una singularidad de la adquisición del tesoro, del derecho sobre el mismo del descubridor y del propietario del fundo, que pueda ser, no ya revocado, sino revocado in dubbio y esté (si se quiere calcar la frase) siempre en suspenso. Todos nuestros derechos y todas nuestras adquisiciones lo están y pueden ser en un cierto momento revocados in dubbio: nuestro estado civil, nuestro nombre, nuestra nacionalidad, nuestra propiedad, nuestros créditos, la herencia ya deferida y aceptada. La certeza matemática está fuera del mundo jurídico, porque está fuera del mundo social. Nos contentamos y nos debemos contentar siempre con una probabilidad. Añade, que el primer error de Perozzi consiste en hablar de revocación, como si se tratase de revocación de la propiedad en sentido técnico-jurídico, de una propiedad adquirida que viene a extinguirse. Nosotros no sostenemos que la adquisición sea revocable cuando se presenta el propietario, sino que la adquisición no ha existido: quien revoca en duda niega el derecho, no lo extingue. El segundo error consiste en exigir no ya la inexistencia, sino la inhallabilidad del propietario, y así si se mantiene la antigüedad del depósito, que es el único elemento que

\footnotetext{
${ }^{6}$ ORTEGA, Derecho Privado Romano, cit., I64; LOZANO, Historia e Instituciones de Derecho Romano, cit., 383 .

${ }^{6}$ PEROZZI, Tra la fanciulla d'Anzio e la Niobide, cit., 263 ss.

${ }^{6}$ BONFANTE, La vera data di un testo di Calpurnio Siculo e il concetto romano del tesoro, cit., I34 ss.; Corso di Diritto Romano. La proprietà, II, 2, cit., I45 s. En el mismo sentido, PANERO, Derecho Romano, cit., 38I.
}

Redur 4 / 2006 
puede hacer presumir la inexistencia, es claro que los casos de descubrimiento del verdadero propietario serán escasos, por no decir imposibles.

2. La definición de Teodosio I.

En opinión de Puliatti ${ }^{66}$, en época postclásica el concepto unitario y específico de tesoro como antiguo depósito oculto de dinero carente de titular se modifica, se amplia y, en cierta medida, se generaliza: junto al dinero (pecunia ) entran en el concepto de tesoro las alhajas (monilia ) y objetos de relevante valor (mobilia). En una constitución del 30 de marzo del año 3I5 Constantino considera específicamente el tesoro como riqueza.

C. Th. Iо, I8, I (Imp. Constantinus A. ad rationales): Quicumque thesaurum invenerit et ad fiscum sponte detulerit, medietatem consequatur inventi, alterum tantum fisci rationibus tradat, ita tamen, ut citra inquietudinem quaestionis omnis fiscalis calumnia conquiescat. Haberi enim fides fas est his, qui sponte obtulerint quod invenerint. Si quis autem inventas opes offerre noluerit et aliqua ratione proditus fuerit, a supra dicta venia debebit excludi.

Añade Puliatti que el término opes adoptado en la disposición es en sí genérico. Ello supone que su valor semántico va más allá de la simple noción de dinero para comprender otro tipo de bienes, imprecisos, pero de valor. La genérica dicción constantiniana se especifica en el pensamiento de Teodosio I, en una constitución promulgada el día 26 de enero del año 380.

C. Th. ıо, I8, 2 (Imppp. Gratianus, Valentinianus et Theodosius A.A.A. ad populum urbis constantinopolitanae)67: Quisquis thesauros et condita $a b$ ignotis dominis tempore vetustiore monilia quolibet casu reppererit, .......

\footnotetext{
${ }^{66}$ PULIATTI, Il «de iure fisci» di Callistrato e il processo fiscale in età severiana, cit., I69 s.

${ }^{67}$ En la inscriptio figuran los nombres de Graciano, Valentiniano y Teodosio, esta indicación ha provocado dudas en la doctrina sobre la autoría de la citada constitución.

SCIALOJA, Teoria della proprietà nel diritto romano, II, cit., 5I, atribuye la constitución a Graciano y Valentiniano.

BUTERA, s.v. Tesoro, cit., 962; VOCI, Modi di acquisto della proprietà, cit., 2I nt. 3; VOLTERRA, Instituciones de Derecho Privado Romano, cit., 333; GUZMAN, Derecho Privado Romano, I, cit., 542; DOMÍNGUEZ, Las pretensiones fiscales sobre los tesoros: Derecho Romano y Código Civil, cit., 377; MALAVÉ, «Pecunia, monilia y mobilia», como objeto del tesoro, cit., 450; DE LAS HERAS, Adquisición del tesoro en el Fuero de Cuenca: bases romanas y evolución posterior, cit., 55, 64, atribuyen la autoría de la constitución a los emperadores que figuran en la inscriptio.

BONFANTE, La vera data di un testo di Calpurnio Siculo e il concetto romano del tesoro, cit., I39; BISCARDI, Studi sulla legislazione del Basso Impero II. Orientamenti e tendenze del legislatore nella disciplina dei rapporti reali, cit., 276 s., la atribuyen a Graciano.

ORTEGA, Derecho Privado Romano, cit., I62; LOZANO, Historia e Instituciones de Derecho Romano, cit., 382, atribuyen esta constitución a los emperadores Graciano, Valentiniano y Valente.

Con mejor criterio, DUPONT, Les constitutions ad populum, en RH, 49 (I97I) 588; SCARCELLA, Una nuova concezione del tesoro alla luce di C.I. Io.I5.I, cit., I96 nt. I9; BUSACCA, s.v. Tesoro, cit., 386 nt. 57, afirman que esta constitución emanada en Tesalónica y dirigida al pueblo de Constantinopla, debe ser atribuida a Teodosio, que en esa ciudad había establecido su cuartel general entre los años 379-382; PULIATTI, Il «de iure fisci» di Callistrato e il processo fiscale in età severiana, cit., I70.
} 
De la citada constitución se pueden extraer los siguientes elementos:

a) consistente, junto al dinero, además, en joyas o alhajas;

b) enterrado;

c) desde tiempo remoto;

d) de dueño desconocido.

Veamos a continuación los diversos elementos que integran la definición Teodosio I y que presentan diferencias respecto de los que componen la definición de Paulo.

\section{I. Condita monilia.}

Teodosio I añade junto a la pecunia, los monilia como objeto del tesoro.

Bonfante $^{68}$ dejó escrito que la oposición entre thesaurus y monilia representa en cierto modo la oposición entre la sociedad antigua y la moderna en orden al tesoro.

Corresponde a Scarcella ${ }^{69}$ el mérito de haber puesto de relieve las razones de esta evolución. Afirma la citada autora que en los primeros siglos del Imperio, la ausencia de una verdadera organización del crédito unido a la fragilidad de las casas romanas para guardar de manera segura los propios capitales, lleva a que tengan que ser enterrados para su conservación o custodia. En este contexto era inevitable que cada vez con más frecuencia se descubriesen cantidades de dinero y, consiguientemente, surge la necesidad de establecer los requisitos jurídicos para que la depositio pecuniae pueda ser considerada tesoro en sentido técnico. A ello responde la definición de Paulo.

La citada autora afirma que las transformaciones económico-sociales, el desarrollo del sistema crediticio y el fenómeno de la devaluación monetaria a partir del siglo III, hacen que ya no resulte rentable el ocultamiento de dinero, sino su inversión en la adquisición de objetos -monilia - que según la conciencia económico-social tenían un valor que el tiempo se encargaba de acrecentar. Hecho que se generaliza como consecuencia de las numerosas invasiones bárbaras, que a partir de la segunda mitad del siglo II sufren las provincias de Europa, Asia Menor, África y Egipto. Con esta sucesión de acontecimientos, a finales del siglo IV, es decir, en tiempos de Teodosio, junto al descubrimiento de pecunia debía ser frecuente el de monilia. A ello, añade Scarcella que desde el punto de vista jurídico no podía entrar sic et simpliciter bajo el régimen jurídico del tesoro (= pecunia) y, además, tampoco podían ser encuadradas en el caso de las «gemmae, lapilli, margaritae inventae in litore maris», sometidas en época clásica al régimen de adquisición de la propiedad por occupatio.

Scarcella ${ }^{70}$ ha destacado que la equiparación bajo el mismo régimen jurídico de los «condita monilia» y el tesoro clásico debió de generar en la práctica gran confusión por dos motivos: en primer lugar, por los distintos requisitos exigidos a efectos de la asimilación; y en segundo lugar, por el hecho de que el término «monilia» es vago, impreciso y, al mismo

68 BONFANTE, La vera data di un testo di Calpurnio Siculo e il concetto romano del tesoro, cit., I39 ss.; Corso di Diritto Romano. La proprietà, II, 2, cit., I29 s.

${ }^{69}$ SCARCELLA, Una nuova concezione del tesoro alla luce di C.I. IO.I5.I, cit., I99 ss.

${ }^{70}$ SCARCELLA, Una nuova concezione del tesoro alla luce di C.I. IO.I5.I, cit., 204 S.

Redur 4 / 2006 
tiempo, poco comprensivo. Observa que si la doctrina le ha atribuido el significado de objeto precioso, lo ha hecho sin tener en cuenta los datos proporcionados por las fuentes, literarias y jurídicas. Las primeras utilizan «monile» con el significado de collar confeccionado con oro, perlas y gemas, y «monilia» con referencia a cualquier adorno precioso hecho con perlas y gemas; las fuentes jurídicas, sin embargo, de manera algo confusa, se limitan a indicar que «monilia» es cualquier cosa distinta de los adornos, de los anillos y, desde luego, de la plata y del oro $^{7 \mathrm{I}}$. Tal situación hacía inevitable que después del descubrimiento de un objeto de valor, se preguntase si era posible considerarlo un «monile»y, consiguientemente, aplicarle el mismo régimen jurídico del tesoro.

${ }^{71}$ SCARCELLA, Una nuova concezione del tesoro alla luce di C.I. IO.I5.I, cit., 204 nt. 48, cita,

D. 34, 2, 32, 7 (Paulus, II ad Vitellium): Titia mundum muliebrem Septiciae legavit: ea putabat sibi legata et ornamenta et monilia, in quibis gemmae et margaritae insunt, et anulos et vestem tam coloriam: quaesitum est, an haec omnia mundo continentur. Scaevola respondit ex his quae proponerentur, dumtaxat argentum balneare mundo muliebri contineri. Afirma que en el citado pasaje los «monilia» son considerados como cualquier cosa distinta de los «ornamenta» y de los «anuli»; además el requisito advertido por Paulo de añadir a «monilia» «in quibus gemmae et margaritae insunt» pone de relieve que el término tenía un significado poco preciso, y

P.S. 3, 6, 6o: Monilibus legatis, aurum vel argentum non debetur, nisi de his quoque manifeste sensisse testatorem posset ostendi.

Para la citada autora, es evidente la preocupación del jurista de aclarar que los «monilia» son algo distinto del oro y de la plata («aurum vel argentum non debetur»). Cita además,

C. Th. 9, 42, 7 (Imppp. Valentinianus, Valens et Gratianus A.A.A. ad Probum P.P.): Si qui intra provinciam pro qualitate delicti stilum proscribtionis incurrerit, per ordinarii officii sollicitudinem bonorum eius indago diligentissime celebretur, ne quid rei privatae commodis per gratiam atque conludium furto subducatur. Et plena describtio conprehendat, quod spatium et quod sit ruris ingenium, quid aut cultum sit aut colatur, quid in vineis olivis aratoriis pascuis silvis fuerit inventum, quae etiam gratia et quae amoenitas sit locorum, quis aedificiis ac possessionibus ornatus, quotve mancipia in praediis occupatis vel urbana vel rustica vel quarum artium generibus inbuta teneantur, quot sint casarii vel coloni, quot boum exercitiis terrarum atque vomeribus inservientium, quot pecorum et armentorum greges et in qua diversitate numerati sint, quantum auri et argenti, vestium ac monilium vel in specie vel in pondere et in quibus speciebus quidve in enthecis sit repertum. Tum demum omnia ea, quae velle nos perspicis, inquisitione constricta rationalis rei privatae tradantur officio nostro nectenda patrimonio. Mox vero ad nos sub litteris publicis iudicis singillatim de omnibus nominatimque perferatur, procul dubio neglegentia multanda. Nam si quid post factam a praedicto officio investigationem rationalis rei privatae, cui inquisitio secunda mandata est, amplius fortassis invenerit, officium fraudulentum ea condemnatione ferietur, ut aliud tantum, quantum fuerat subtractum, ex propriis facultatibus inferat.

C. Th. I6, 2, 27 (Imppp. Valentinianus, Theodosius et Arcadius A.A.A. Tatiano P.P.): Nulla nisi emensis sexaginta annis, cui votiva domi proles sit, secundum praeceptum apostoli ad diaconissarum consortium transferatur. Tum filiis suis, curatore, si id aetas poscit, petito, bona sua idoneis sedula religione gerenda committat, ipsa tantum praediorum suorum reditus consequatur, de quibus servandi abalienandi donandi distrahendi relinquendi vel quoad superest vel cum in fata concedit et libera ei voluntas est, integra sit potestas. Nihil de monilibus et superlectili, nihil de auro argento ceterisque clarae domus insignibus sub religionis defensione consumat, sed universa integra in liberos proximosve vel in quoscumque alios arbitrii sui existimatione transcribat ac si quando diem obierit, nullam ecclesiam, nullum clericum, nullum pauperem scribat heredes. Careat namque necesse est viribus, si quid contra vetitum circa personas specialiter conprehensas fuerit a moriente confectum. Immo si quid ab his morienti fuerit extortum, nec tacito fideicommisso aliquid clericis in fraudem venerabilis sanctionis callida arte aut probosa cuiuspiam coniventia deferatur; extorres sint ab omnibus quibus inhiaverant bonis. Et si quid forte per epistulam codicillum donationem testamentum, quolibet denique detegitur genere conscribtum erga eos, quos hac sanctione submovimus, id nec in iudicium devocetur, sed vel ex intestato is, qui sibi competere intellegit, statuti huius definitione succedat, si quis se agnoscit filium, si quis probat propinquum, si quis denique vel casu vel iudicio, pro solido pro portione, heres legatarius fideicommissarius apertis deprehenditur codicillis, fruatur fortunae munere, conscientiae suae fructu et submotis his adque deiectis in hereditariis corporibus potestate utatur heredis. 
Por otra parte, el ocultamiento es puesto de relieve con la expresión «condita monilia». Como afirma la doctrina ${ }^{72}$, el ocultamiento es indicado indiferentemente en las fuentes con los verbos «deponere» $\mathrm{y}$ «condere» con un significado equivalente.

\subsection{Tempore vetustiore.}

A diferencia de Paulo que exigía para la pecunia un «vetus depositio», Teodosio I exige para los monilia un condere «tempore vetustiore».

En opinión de Scarcella ${ }^{73}$, la razón reside en que para los «monilia», esto es, los adornos realizados con oro, gemas y perlas, probablemente objetos no fungibles (al no existir la producción en serie), únicamente un ocultamiento no «vetus» sino «vetustior» hacía disminuir la posibilidad de que alguno pudiera probar su condición de propietario de las joyas descubiertas, posibilidad que no se puede excluir totalmente. Añade que la circunstancia de que en C. Th. IO, I8, 2 se utilice el comparativo absoluto «tempore vetustiore» con la finalidad de equiparar bajo el mismo régimen jurídico los «condita monilia» y el «thesaurus», mientras que Paulo en su definición (D. 4I, I, 3I, I) utiliza el adjetivo «vetus» en su grado normal, puede considerarse emblemático de la voluntad imperial de exigir un requisito distinto. Quizá con tal expresión el legislador ha querido probablemente decir no sólo que el ocultamiento de los monilia debía de haberse realizado en tiempos antiguos, sino que la antigüedad exigida era mayor, distinta respecto de aquella jurídicamente necesaria para la depositio pecuniae.

\subsection{Ignotis dominis.}

Teodosio I exige que se trate de «dueño desconocido», mientras que Paulo exigía la inexistencia del propietario. A este propósito, afirma Ortega ${ }^{74}$ que la diferencia es tan sólo formal. Una cosa escondida hace tiempo por dueños desconocidos, en realidad no tiene dueño; verdad es que puede tenerlo, pero descubrir su identidad aparece como virtualmente imposible: de no apparentibus et de non existentibus, eadem est ratio.

En opinión de Scarcella ${ }^{75}$, como hemos visto, la diferencia reside en el distinto objeto del ocultamiento que hace variar los presupuestos jurídicos necesarios para la aplicación del régimen jurídico del tesoro.

Para Busacca ${ }^{76}$, en época postclásica el tesoro deja de ser considerado como una res nullius y, por tanto, sometido al régimen de adquisición de la ocupación; ahora viene considerado como res nullius en su nuevo significado de cosa no susceptible de ser objeto de relaciones jurídico privadas, siendo posible ingresar en el patrimonio privado mediante la inventio. A la luz de todos estos motivos parece comprensible que con el fin de

$7^{2}$ SCARCELLA, Una nuova concezione del tesoro alla luce di C.I. IO.I5.I, cit., I98 nt. 28; ORTEGA, Derecho Privado Romano, cit., i63.

${ }^{73}$ SCARCELLA, Una nuova concezione del tesoro alla luce di C.I. IO.I5.I, cit., 203 s.

${ }^{74}$ ORTEGA, El concepto romano de tesoro y el artículo 352 del código Civil, cit., 749.

${ }^{75}$ SCARCELLA, Una nuova concezione del tesoro alla luce di C.I. IO.I5.I, cit., 202 S.

${ }^{76}$ BUSACCA, s.v. Tesoro, cit., 389 .

Redur 4 / 2006 
individualizar los requisitos del tesoro se haya tomado en consideración no la inexistencia del dominus, sino su falta de conocimiento.

\section{La definición de León II y Zenón.}

La falta de seguridad en cuanto a si el objeto descubierto podía o no considerarse jurídicamente como un tesoro derivada de la utilización del impreciso término monilia, debió de provocar un gran número de consultas a la cancillería imperial que, entre otras razones, debieron inducir a León II y a Zenón a publicar el Io de octubre del año 474 una constitución dirigida a eliminar toda duda sobre el concepto de tesoro, sobre las modalidades de búsqueda y descubrimiento y sobre su adquisición ${ }^{77}$.

C. J. Iо, I5, I (Impp. Leo78 et Zeno A.A. Epinico consulari): .....thesaurum (id est condita ab ignotis dominis tempore vetustiore mobilia) ${ }^{p 9}$...

Por lo que se refiere al concepto de tesoro, destacar que la única novedad que introduce León II con relación a la constitución de Teodosio I es la relativa a la ampliación del objeto: cualquier cosa mueble ${ }^{80}$ de valor.

Perozzi $^{8 \mathrm{r}}$ ha dudado que el Derecho romano exigiese el requisito del valor del objeto. En su opinión, ello nada aporta al régimen de adquisición y, por el contrario, genera una incerteza y, consiguientemente, un amplio campo al arbitrio judicial: ya que, cuándo

77 De León II y Zenón, a través del Código de Justiniano, nos han llegado seis constituciones: C. J. 2, 7, I6 (Impp. Leo iunior et Zeno A.A. Iustiniano P.U.); 2, 7, I7 ( Imp. Zeno A. Paulo P.P.); I, I4, II (Impp. Leo et Zeno A.A.); ıo, I5, I (Impp. Leo et Zeno A.A. Epinico Consulari); I2, 25, 4 ( Impp. Leo et Zeno A.A. Marinao Comiti et Magistro officiorum); I2, 29, 2 (Impp. Leo et Zeno A.A. Eusebio Magistro officiorum).

79 En opinión de PULIATTI, Il «de iure fisci» di Callistrato e il processo fiscale in età severiana, cit., I70 s., el inciso «id est condita ab ignotis dominis tempore vetustiore mobilia» tiene toda la apariencia de una glosa modelada sobre la dicción teodosiana de C. Th. 10. I8. 2, o una de tantas interpolaciones introducidas por los compiladores sobre textos de la legislación imperial, como prueba la lectura paralela de los códigos teodosiano y justinianeo. La novedad de la disposición de León II y Zenón consiste en superar la dicotomía pecunia-monilia, en un concepto de tesoro polivalente y distintamente unitario respecto de aquel clásico, mientras que el término mobilia refleja el pensamiento justinianeo.

80 PAMPALONI, Il concetto giuridico del tesoro, cit., IIO; ROTONDI, I ritrovamenti archeologici e il regime dell'acquisto del tesoro, cit., 35I; BONFANTE, Corso di Diritto Romano. La proprietà, II, 2, cit., I37; SCIALOJA, Teoria della proprietà nel diritto romano, II, cit., 52; BISCARDI, Studi sulla legislazione del Basso Impero II. Orientamenti e tendenze del legislatore nella disciplina dei rapporti reali, cit., 300; LONGO, Corso di Diritto Romano. I diritti reali, cit., I2I; MAYER-MALY, Der Schatzfund in Justinians Institutionen, cit., II2, atribuyen la constitución a León el Grande.

Cfr. otros autores como SCARCELLA, Una nuova concezione del tesoro alla luce di C.I. Io.I5.I, cit., I88 nt. 3, afirma que León II sucede a León el Grande después de un breve período de corregencia (octubre del 473 al I8 de enero del 474); BUSACCA, s.v. Tesoro, cit., 387 nt. 62; Qualche osservazione sulle innovazioni introdotte dai divi fratres nel regime giuridico del tesoro, cit., I49 nt. 53, afirma que accede al trono en enero del año 474, con siete años de edad; PULIATTI, Il «de iure fisci» di Callistrato e il processo fiscale in età severiana, cit., I70; DE LAS HERAS, Adquisición del tesoro en el Fuero de Cuenca: bases romanas y evolución posterior, cit., 55.

${ }^{8 \mathrm{I}}$ PEROZZI, Contro l'istituto giuridico dell'acquisto del tesoro, cit., 290. 
una cosa se podrá decir que es de valor, y cuándo no. Añade ${ }^{82}$ que el código justinianeo no habla más que de mobilia, palabra que viene a sustituir intencionadamente a monilia del código teodosiano. Puesto que el Código (justinianeo) es posterior al Digesto y se le puede considerar preferente, es claro que si el Digesto habla de pecunia, el requisito fue modificado por el Código, extendiendo el concepto de tesoro a cualquier cosa mueble, de valor o no.

En esta línea, Longo ${ }^{83}$ considera que los textos no exigen que se trate de una cosa de valor. Al contrario, este requisito es indicado por algunos autores como relevante en el concepto de tesoro, pero no es exacto. Añade que una regulación del tesoro es necesaria ya que la cosa presenta algún interés, o bien provoca un conflicto de intereses. En la práctica naturalmente que se tratará de cosas de cierto valor, e incluso de un valor importante, y esto explica que la institución haya asumido el nombre de tesoro que en el lenguaje común se utiliza para referirse a las cosas preciosas. Estas observaciones advierten contra el peligro de confundir el concepto jurídico y el concepto vulgar de tesoro, y de no tener en cuenta los motivos que han llevado a la regulación de esta hipótesis de adquisición de la propiedad.

En opinión de Bonfante ${ }^{84}$, es dudoso el canón exegético al que acude Perozzi, ya que las tres partes de la compilación debieron ser consideradas como emitidas en un mismo día, aunque es cierto que el carácter más moderno del Código se impone algunas veces. Por otra parte, la modificación no tiene aquel significado que Perozzi le atribuye. Mobilia es sustituido intencionadamente, pero no para eliminar el concepto de valor, sino para reunir en una misma definición el thesaurus, es decir, la pecunia y los monilia, diferenciados en el código teodosiano. En realidad, concluye, este requisito del valor es natural tanto en el derecho justinianeo como en el derecho prejustinianeo. Tiene para el jurista un significado económico, no crematístico, y se puede considerar inherente al concepto de cosa.

Para Ortega ${ }^{85}$, el valor no es tanto un requisito del concepto de tesoro, sino más bien una cualidad natural implícita en la misma expresión tesoro.

La noción de valor conduce necesariamente a la medida del mismo y, por tanto, al peligro advertido por Bonfante ${ }^{86}$ de no considerar tesoro el objeto que tenga un valor no relevante. Por eso, para Scialoja ${ }^{87}$ no es exacto exigir que la cosa tenga un alto valor, jurídicamente han de ser tratadas igual. Para Ortega y Lozano ${ }^{88}$ hablar de un alto valor sería arriesgado, ante todo por los condicionamientos sociales, económicos y políticos que habría que analizar, después está el hecho según el cual, el valor de un mismo objeto varía enormemente de una época a otra: pensemos en un depósito de monedas de escaso valor adquisitivo en su época, que adquiere un enorme valor como antigüedad, por su rareza numismática. Así pues, el término valor es siempre relativo, y mejor que de un alto valor sería preferible hablar de aquél necesario y suficiente para provocar, en su caso, un conflicto de intereses, que haga necesaria la intervención del derecho. Si el descubrimiento no

${ }^{82}$ PEROZZI, Tra la fanciulla d'Anzio e la Niobide, cit., $262 \mathrm{~s}$.

${ }^{83}$ LONGO, Corso di Diritto Romano. I diritti reali, cit., I05 s.

${ }^{84}$ BONFANTE, Corso di Diritto Romano. La proprietà, II, 2, cit., I39 S.

${ }^{85}$ ORTEGA, El concepto romano de tesoro y el artículo 352 del Código Civil, cit., 747.

${ }^{86}$ BONFANTE, Corso di Diritto Romano. La proprietà, II, 2, cit., I4O.

${ }^{87}$ SCIALOJA, Teoria della proprietà nel diritto romano, II, cit., 49.

${ }^{88}$ ORTEGA, Derecho Privado Romano, cit., I64 s.; El concepto romano de tesoro y el artículo 352 del Código Civil, cit., 747 s.; LOZANO, Historia e Instituciones de Derecho Romano, cit., 384.

Redur 4 / 2006 
despierta interés alguno (arqueológico o económico) ni surge el concepto de tesoro, ni se plantea problema jurídico sobre su adquisición. 